\title{
Preparation and Stress Fringe Map Change law of light Elastic-plastic Material in Deformation Object
}

\author{
CHEN JIA-HUI \\ School of Pharmaceutical, China \\ Pharmaceutical University
}

\author{
CHEN Lin \\ School of Material and Metallurgy, \\ Inner Mongolia University of Science \\ and Technology
}

\author{
TIAN Zhong-liang \\ School of Material and Metallurgy, \\ Inner Mongolia University of Science \\ and Technology
}

\begin{abstract}
Based on the photo-elastic method, four groups of different ratio light elastic-plastic material were prepared by changing the epoxy resin, the firming agent, the plasticizer mass ratio; and the light elastic-plasticity material stress-strain curve and its elastic modulus $\mathrm{E}$ and Poisson's ratio were obtained through the stretch experiment. The light elastic-plastic rail models were made by $1: 5$, and the computation analyzes stress distribution of the rail head of the heavy rail and carried on the static examination. The stress stripe chart change rule of the light elastic-plasticity material during load and unload process was observed.
\end{abstract}

Key words-light elastic-plastic; material preparation

\section{INTRODUCTION}

The photo-elastic material is mainly used to study the stress distribution of elastic deformation, while the photo-plastic deformation is mainly used to study the stress distribution of plastic deformation. But in the practical live, many components are not only elastic deformation, but also plasticity deformation, for example, heavy rail straightening process. Therefore, we can make a sort of photo-plastic material to study plastic deformation stress and residual stress distributions of components deformation that is mainly elastic-plastic deformation, which has quite important application value to study stress and strain connection along with stress distribution in the components elastic-plastic deformation process of practical production.

And based on the photo-elastic method, the light elastic-plastic stress material is made by changing photo-elastic material distribution. The light elastic-plastic rail straightening model is made by 1:5 ratio. And the computation analyzes stress distribution of the deformation object and carries on the static examination.

The light elastic-plastic material mainly has the epoxy resin, the butylene two estolide, the dibutyl phthalate resin. The light elastic-plastic material can take place elastic-plastic deformation under load condition through changing mass ratio of its basis. The stress stripe chart change rules of the different distribution ratio light elastic-plasticity material during load and unload process are investigated.

The authors would like to thank the institutions science foundation of Inner Mongolia (NJ09089) and the national natural science foundation of China (National nature fund: 50765004) for subsidization.

\section{PREPARATION OF THE LIGHT ELASTIC-PLASTICITY MATERIAL PREPARATION}

The different allocated proportion light elastic-plasticity material and isochromatic line change circs during load and unload process are investigated, as well as how to control patterns retention time to realize predigestion of experimental process.

Several groups of the different allocated proportion light elastic-plasticity material are made by means of the epoxy resin using low molecular weight polymer of both hydroxybenzene A and epoxy allyl chloride, the firming agent: the butylene two estolide and the plasticizer: the dibutyl phthalate resin, such as table one, which can determine the material stripe value $\mathrm{f}$, so as to analyze material nature.

\begin{tabular}{|c|c|c|c|c|}
\hline \multicolumn{5}{|l|}{ Number } \\
\hline Component & 1 & 2 & 3 & 4 \\
\hline the epoxy resin & 100 & 100 & 100 & 100 \\
\hline the butylene two estolide & $25-45$ & $30-50$ & $30-50$ & $25-45$ \\
\hline the dibutyl phthalate resin & $25-35$ & $50-70$ & $60-90$ & $40-60$ \\
\hline N-N-dimethylaniline & $0.1-0.3$ & $0.2-0.5$ & $0.3-0.6$ & $0.2-0.4$ \\
\hline
\end{tabular}

Pouring the epoxy resin down in the beaker to thaw, according to calefaction curve to cast, so as to carry on solidification in the range of temperature of $42 \sim 44^{\circ} \mathrm{C}$ for the first time. Carry on solidification at $120^{\circ} \mathrm{C}$ for the second time until model stripping when it entirely gel. Process the epoxy resin solidification, so as to observer that whether it has original stress on the photo-elastic instrument. If it has original stress, it should be carried on annealing treatment.

\section{MEASURE OF THE LIGHT ELASTIC-PLASTIC MATERIAL STRIPE SERIES}

\section{A. Measure of equal difference line (isochromatic line)}

Put four groups of the light-elastic material on the light-elastic instrument and load it with quantitative force, so 
we can screen isochromatic stripe chart with a digital camera. This experiment use circular polarizer with nature light irradiation, so we can screen chromatic stripe directly. Figure one is isochromatic line taken directly, and figure two is isochromatic line processed.

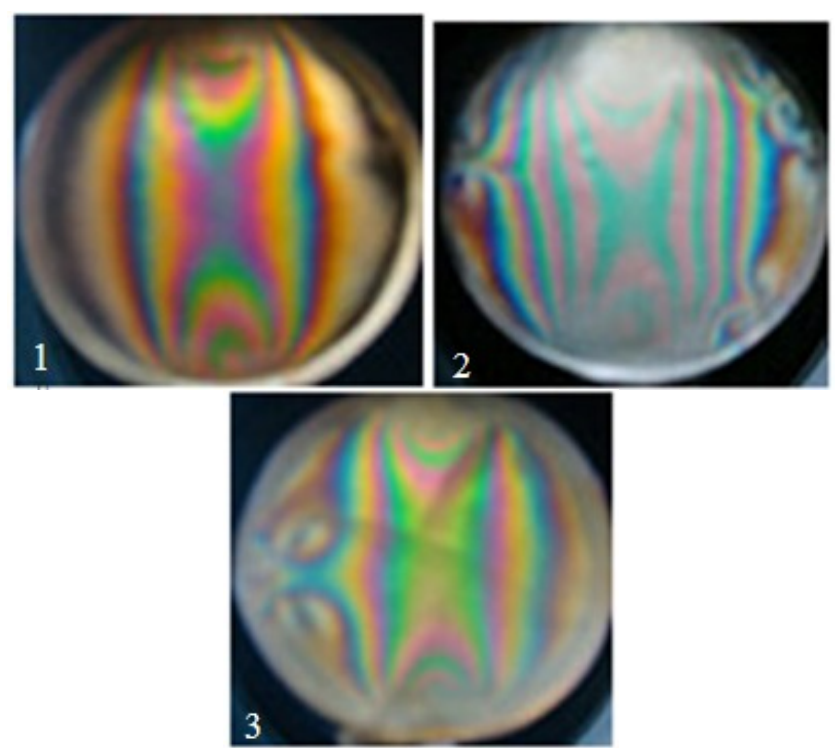

Fig.1 $1^{\#}-3^{\#}$ Isochromatic line stripe chart of the light-elastic material disc in $20 \mathrm{~kg}$ stress condition
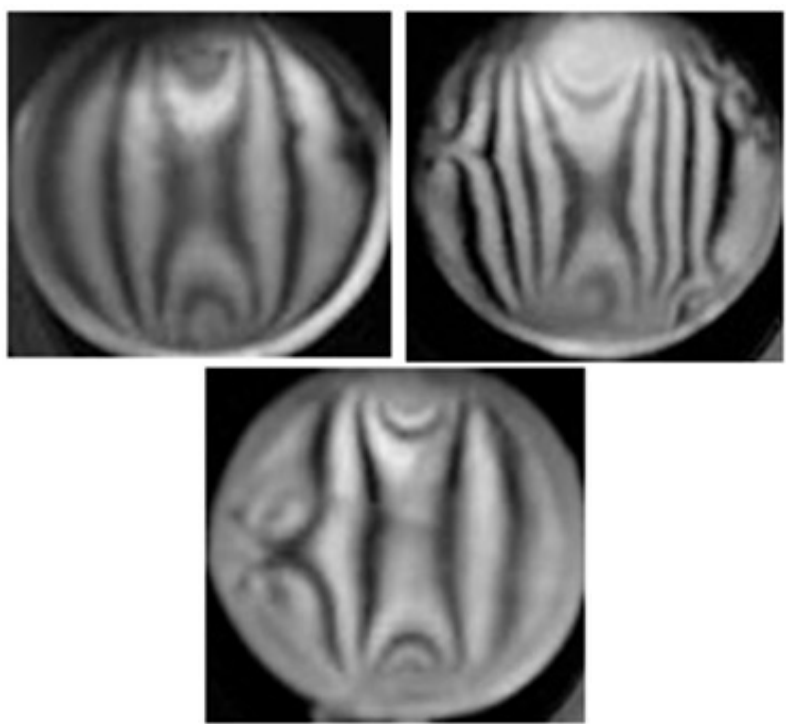

Fig.2 $1^{\#}-3^{\#}$ Isochromatic line stripe chart of the light-elastic material disc in $20 \mathrm{~kg}$ stress condition

\section{B. Residual stress of the light elastic-plastic material wafer}

Through the comparative analysis of $2^{\#}$ sample, the experimental results show that when the photo-elastic material distribution ratio is the epoxy resin: the firming agent: the plasticizer $=100: 30-50: 50-70$, so the pattern can keep for 15 minutes, and $1^{\#}$ sample can keep for about 7-8 minutes. When continue to increase the plasticizer and the firming agent, the pattern keep short time.
Taken $2^{\#}$ sample for research object, putting the $2^{\#}$ light elastic-plastic material on the numeral light-elastic, unloading after obtaining rank chromatic line through load, observe change circs of the light elastic-plastic material stripe number and screen one time in each minute, so the photos will be combined into figure 3 .

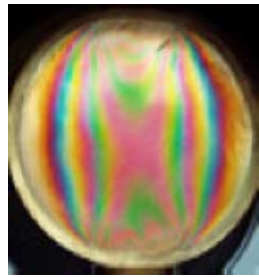

$\mathrm{t}=1 \mathrm{~min}$

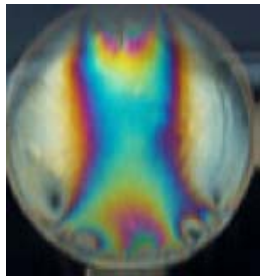

$\mathrm{t}=4 \mathrm{~min}$

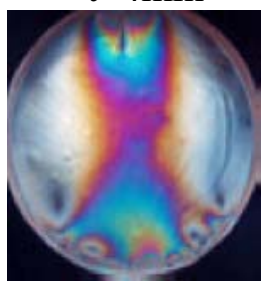

$\mathrm{t}=7 \mathrm{~min}$

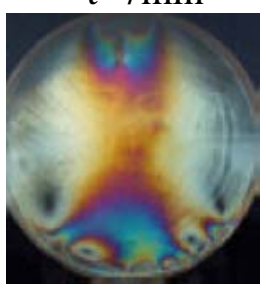

$\mathrm{t}=10 \mathrm{~min}$

$\mathrm{t}=13 \mathrm{~min}$

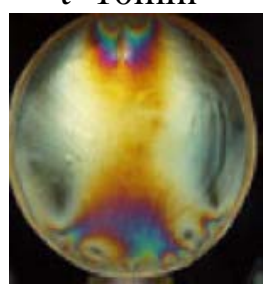

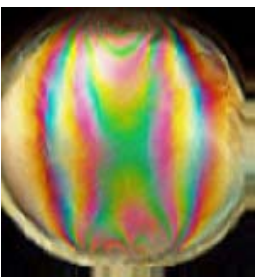

$\mathrm{t}=2 \mathrm{~min}$

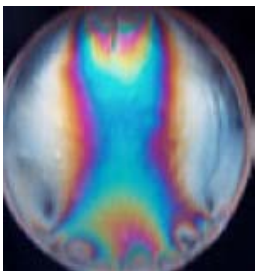

$\mathrm{t}=5 \mathrm{~min}$

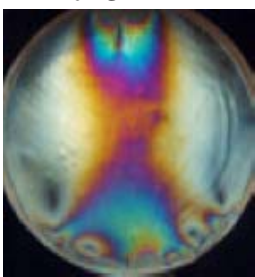

$\mathrm{t}=8 \mathrm{~min}$

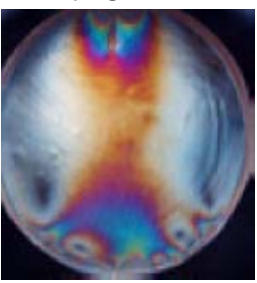

$\mathrm{t}=11 \mathrm{~min}$

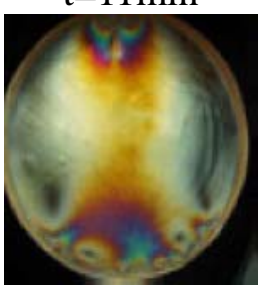

$\mathrm{t}=14 \mathrm{~min}$

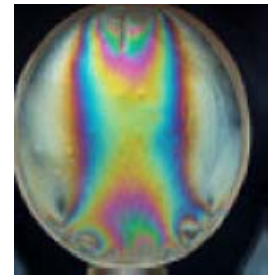

$\mathrm{t}=3 \min$

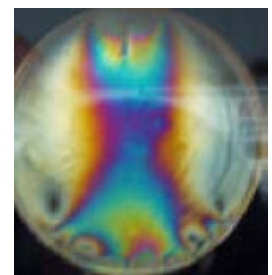

$\mathrm{t}=6 \mathrm{~min}$

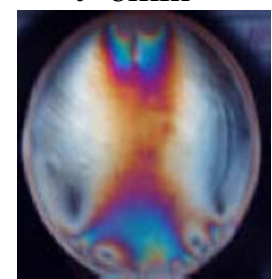

$\mathrm{t}=9 \mathrm{~min}$

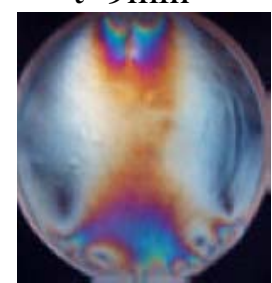

$\mathrm{t}=12 \mathrm{~min}$

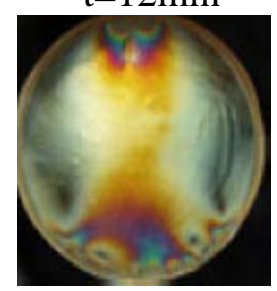

$\mathrm{t}=15 \mathrm{~min}$
Fig.3 Isochromatic line chart of $2^{\#}$ sample unloaded each one minute

C. Mechanical properties of the different distribution ratio epoxy resin mechanical properties

Make the epoxy resin of about $1 \mathrm{~cm}$ in diameter, $20 \mathrm{~cm}$ tall, then test mechanical properties by means of the stretch experiment and set out the stress- strain curve of $1^{\#} 、 2^{\#} 、 3^{\#}$ samples and calculation obtains its elastic modulus $\mathrm{E}$ and Poisson's ratio as shown in table 2. 
TABLE 2 THE ELASTIC MODULUS VALUE OF THE LIGHT ELASTIC-PLASTIC MATERIAL

\begin{tabular}{cccc}
\hline 弹性模量 & $1^{\#}$ & $2^{\#}$ & $3^{\#}$ \\
\hline $\mathrm{E}(\mathrm{MPa})$ & 32 & 25.5 & 20 \\
\hline$\mu$ 值 & 0.277 & 0.357 & 0.706 \\
\hline
\end{tabular}

From the above result we can see that when Poisson's ratio of $1^{\#} 2^{\#}$ material and Poisson's ratio of steel is near and the firming agent is 25-50, the Poisson's ratio will increase along with the plasticizer increasing. The experiments show that choosing $1^{\#}, 2^{\#}$ samples to make rail model is reasonable.

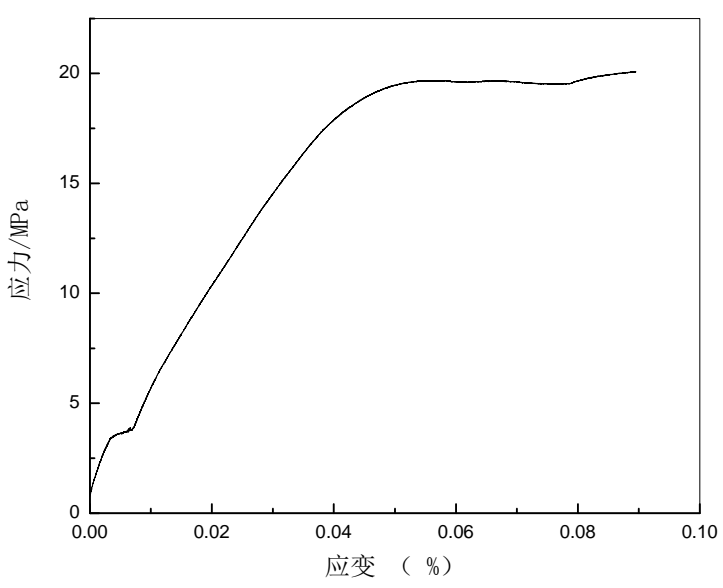

Fig.4 1 $1^{\#}$ Stress-Strain curve

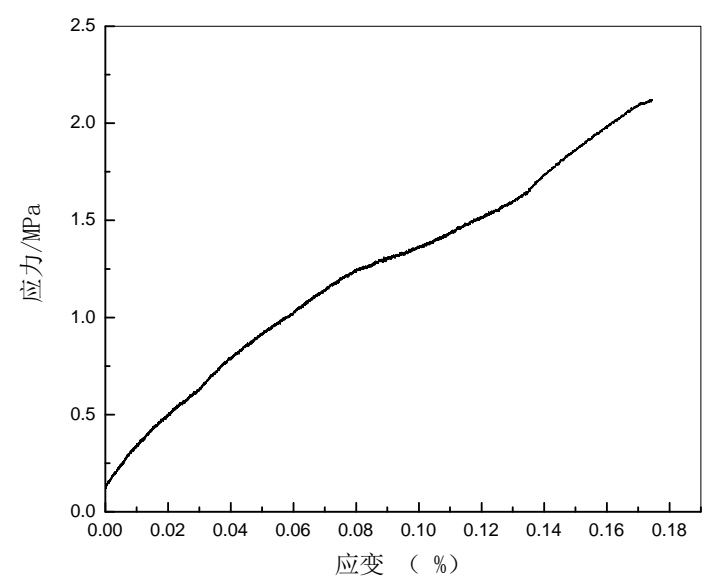

Fig.5 2 $2^{\#}$ Stress-Strain curve

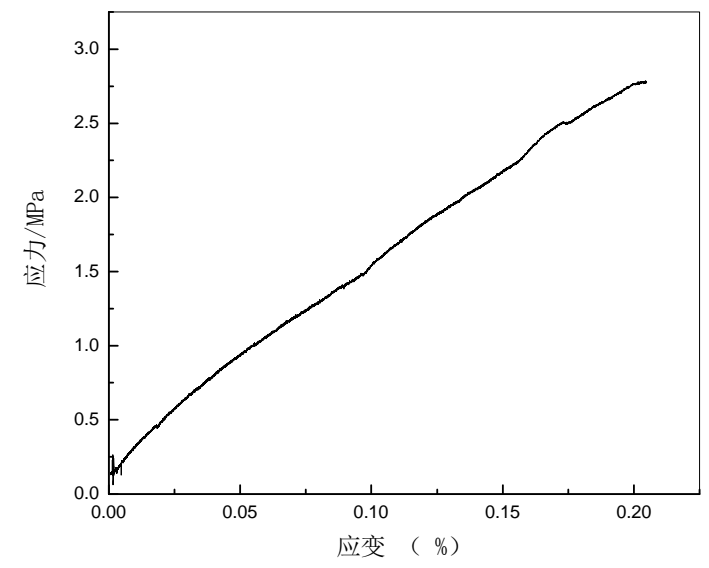

Fig.6 $3^{\#}$ Stress-Strain curve

According to Fig.4. Fig.5, 1\# has apparent elastic stage and the plastic stage, so does 2\#. From Fig.6, we can see that, Epoxy proportion $3 \#$ is dominated by the plastic stage, instead of the apparent elastic stage. In contrast, the Stress-strain curve of steel and light elastic-plastic material proportion $1 \#$ and $3 \#$ are similar, moreover, $1 \#$ is more appropriate to deform steel in room temperature.

\section{CONCLUSION}

(1) The light elastic-plastic material of different plasticizer proportion can occur obvious clear elastic-plastic deformation, its tensile strength will decrease with plasticizer increasing. When the epoxy resin: the firming agent: the plasticizer $=100: 25-45: 25-35$, the stress- strain curve of light elastic-plastic material's is similar to steel's and the Poisson's ratio of $1^{\#}$ light elastic-plastic material is similar to steel's, according with similar theory. This proportion can meet the need of the light elastic-plastic material simulating rail straightening deformation, which provide Simulation of elastic-plastic deformation of steel with feasibility.

(2) The $1^{\#}$ sample of proportion of $100: 30-50: 50-70$ whose inner stress stripe can reserve for long time after unloading. We can research inner residual stress of the component of elastic-plastic deformation with the material's peculiarity.

\section{REFERENCES}

[1] GU Shao-de, ZHANG Hua. Freezing stress research of the initial stress structure in the three dimension light-elasticity [J]. experimental mechanics, 2004, 19(1): 120-124

[2] LIN Zhi-ping, XIE Shui-sheng, CHENG Jun. Experimental method of metal plastic deformation[M].Beijing: Metallurgy Industry Press, 2002. 